\title{
ECO-FICCIONES AMERICANAS: CRISIS AMBIENTAL Y SOCIAL EN LA NOVIA OSCURA (1999) DE LAURA RESTREPO Y LE CLUB DES MIRACLES RELATIFS (2016) DE NANCY Huston
}

\author{
DES ÉCO-FICTIONS AMÉRICAINES : CRISES \\ ENVIRONNEMENTALE ET SOCIALE DANS $L A$ \\ NOVIa oscuRa (1999) DE LAURA Restrepo \\ ET LE CLUB DES MIRACLES RELATIFS (2016) DE \\ NANCY Huston
}

Kate Averis ${ }^{1}$

\begin{abstract}
Artículo derivado de la investigación "Acercamiento comparatista de ecoficciones americanas", cuyos resultados previos fueron publicados en el artículo Averis, K. (2018). American Narratives of Social and Environmental Crisis: Laura Restrepo's La novia oscura (1999) and Nancy Huston's Le Club des miracles relatifs (2016). Journal of Romance Studies 18 (3), pp. 357375.
\end{abstract}

Cómo citar este artículo: Averis, K. (2019). Eco-ficciones americanas: crisis ambiental y social en La novia oscura (1999) de Laura Restrepo y Le Club des miracles relatifs (2016) de Nancy Huston. Estudios de Literatura Colombiana 45, pp. 105-122. DOI: https:// doi.org/10.17533/udea.elc.n45a06

katherine.averis@udea.edu.co

Universidad de Antioquia, Colombia

Recibido: 13.02 .2019

Aprobado: 19.04.2019

Copyright: $\odot 2019$ Estudios de Literatura Colombiana. Este es un artículo de acceso abierto distribuido bajo los términos de la Licencia Creative Commons Atribución No comercial - Compartir igual 4.0 Internacional
Resumen: este artículo analiza la relación entre degradación ambiental y crisis social en dos eco-ficciones americanas recientes: La novia oscura (1999) de Laura Restrepo y Le Club des miracles relatifs (2016) de Nancy Huston. Adoptando un acercamiento comparatista y ecocrítico, el análisis demuestra las intersecciones entre la consciencia ecológica y las estrategias narrativas que se observan en estas dos narrativas que presentan crisis ambientales y sociales fundadas en las relaciones entre degradación ambiental, masculinidades hegemónicas y violencia de género. El análisis concluye con una discusión de esta tríada en relación a las ecologías naturales, culturales y humanas de las dos novelas.

Palabras clave: eco-ficción; Laura Restrepo; La novia oscura; Nancy Huston; Le Club des miracles relatifs.

Résumé : et article analyse la relation entre dégradation environnementale y crise sociale dans deux éco-fictions américaines récentes: La novia oscura (1999) de Laura Restrepo y Le Club des miracles relatifs (2016) de Nancy Huston. En adoptant une approche comparatiste et écocritique, l'analyse démontre les croisements entre la conscience écologique et les stratégies narratives que l'on observe dans ces deux romans qui présentent des crises environnementales et sociales fondées sur le rapport entre dégradation anvironnementale, masculinités hégémoniques et violence du genre. Lanalyse conclut avec une discusión de cette triade en relación aux écologies naturelles, culturelles et humaines des deux romans.

Mots clés : éco-fiction; Laura Restrepo; La novia oscura; Nancy Huston; Le Club des miracles relatifs. 


\section{Introducción}

El tono de crisis que subyace a Le Club des miracles relatifs (2016) de Nancy Huston se replicó en las semanas siguientes a su publicación cuando se desató un incendio inmenso en Alberta, la provincia natal de esta autora canadiense. Desencadenado el 1 de mayo 2016 cerca de las explotaciones de las arenas bituminosas de Fort McMurray, el incendio provocó el desplazamiento de 80000 habitantes de la zona y se extendió por 1500000 acres en el norte de las provincias canadienses de Alberta y Saskatchewan. El alcance de la catástrofe fue tal que no se declaró controlado hasta el 5 de julio 2016 y no se extinguió de manera completa hasta la primavera del año siguiente. Este evento climático extremo fue asociado por algunos comentaristas de los ambientes mediáticos, científicos y políticos canadienses a los cambios observados en los últimos registros meteorológicos, lo que provocó animados debates sobre la relación entre el calentamiento global, el cambio climático y este desastre natural sin precedentes. La novela de Huston, ambientada en una versión ficcionalizada de Fort McMurray, indaga en la expansión reciente de la industria petrolera en las arenas bituminosas canadienses y en su impacto ambiental y social. Asimismo, un tono crítico también subyace a La novia oscura (1999) de Laura Restrepo, publicada casi dos décadas antes. En esta novela, Restrepo dirige una mirada retrospectiva a la violencia política que se desató alrededor de la industria petrolera en Barranquilla en los años 40 para examinar contiguamente sus impactos sociales y ambientales.

Nancy Huston (1953, Calgary) y Laura Restrepo (1950, Bogotá) son dos figuras mayores de sus respectivas literaturas nacionales, aunque la primera no es aún muy leída en Colombia. En sus extensas obras literarias, ambas autoras han abordado preocupaciones surgidas de sus entornos locales para abordar problemáticas globales: desde el desplazamiento y el exilio como efecto de conflictos locales e internacionales, hasta el impacto de la actividad humana sobre el ecosistema del planeta. Las obras que son el objeto del presente análisis indagan en los vínculos entre crisis ambiental y social en las comunidades mineras ahí retratadas, y por lo tanto se pueden considerar obras de "eco-ficción", definida por Jim Dwyer (2010) como ficción que trata las relaciones entre la humanidad y su entorno físico y que varía en la medida en que cuestiones ecológicas constituyen el enfoque primario o el fondo temático de la trama (p. 2). Publicado en un clima de concientización de la amenaza del calentamiento global a la 
sostenibilidad ecológica del planeta, Le Club des miracles relatifs hace parte de una tendencia de eco-ficciones de principios del siglo XXI originarias de países industrializados del hemisferio norte que son responsables de la mayor parte del calentamiento global que contribuye al cambio climático (David, 2016, p. 29) de la que Flight Behaviour (2012) de Barbara Kingsolver es ejemplar. Por su parte, la autora colombiana anticipa desde fines del siglo $\mathrm{xx}$ la actual preocupación por la sostenibilidad ecológica en el contexto de la producción literaria de los llamados países en vía de desarrollo, donde, a pesar de tener una experiencia más directa e inmediata del impacto del cambio climático, no se ha observado la misma proliferación de ecoficciones. Si por un lado Le Club des miracles relatifs pone en primer plano la explotación de las arenas bituminosas para denunciar su impacto sobre el medio ambiente y las relaciones humanas, La novia oscura, por el otro, ofrece un acercamiento ecológico donde las preocupaciones políticas $\mathrm{y}$ sociales del siglo $\mathrm{xx}$ colombiano ocupan el primer plano, demostrando así la variación en el enfoque ecológico observada por Dwyer.

Si los textos literarios de principios del siglo xxi se sitúan en un contexto ecológico en plena evolución, lo mismo ocurre con sus lectores y críticos. Andreas Malm (2017) resalta la influencia del contexto ecológico actual sobre prácticas de lectura al afirmar que el calentamiento global cambia todo, incluso la lectura misma de la literatura (p. 125). Según este ecocrítico, los lectores estarán cada vez más implicados en situaciones que simulan los efectos del cambio climático de los que son testigos. Si, como afirma Malm, las prácticas de lectura son influenciadas por su contexto ecológico, lo mismo sucede con las prácticas críticas, como lo demuestra la emergencia reciente de trabajos críticos ecológicos sobre La novia oscura. Mientras los primeros enfoques críticos sobre esta novela resaltaron el contexto histórico de la violencia política (Lindsay, 2003), sus características postcoloniales y postmodernas (Davies, 2007) y la construcción de género (Martin, 2008), los acercamientos críticos más recientes destacan su representación del ambiente natural (Mutis, 2013; 2014). Al comparar la consciencia ecológica de La novia oscura con la urgencia —en la producción y el tono- presente en Le Club des miracles relatifs, este análisis busca recalcar las similitudes en el tratamiento de las crisis ambientales y sociales en estos dos textos, sin obviar las diferencias importantes entre sus respectivos contextos regionales y literarios. De este modo, propone un acercamiento transnacional a la crítica literaria de ecoficciones, que hasta ahora ha sido 
dominada por paradigmas propuestos desde el mundo anglófono. Si la crítica ecológica de la literatura colombiana ha sido poca o casi nula, la de literaturas en francés tampoco ha sido expansiva. Stéphanie Posthumus (2012) encuentra los orígenes de esta carencia en la reticencia de la crítica en lengua francesa de acoger el realismo y el compromiso que caracterizan las ecoficciones contemporáneas. El presente trabajo busca responder al imperativo, identificado por Laura Barbas-Rhoden (2014), de adoptar metodologías transnacionales en la práctica de la ecocrítica. Con este fin, aproxima dos novelas escritas en las dos últimas décadas desde el sur y el norte del continente americano, en lengua castellana y francesa, que serán analizadas en un marco interpretativo de la ecocrítica latinoamericana y francófona, además de la anglófona que ha dominado el campo. Al situar estas novelas en una genealogía de narrativas americanas de ecoficción, la comparación demuestra el carácter inherentemente transnacional del género que refleja la dimensión global de los dilemas presentados. El estudio de los vínculos entre las crisis ambientales y sociales provocadas por las industrias mineras que operan en el norte y el sur del continente americano es aún más pertinente a la luz de las actividades "predatorias" de empresas mineras canadienses en Colombia en las últimas décadas (Gordon \& Webber, 2008).

Dividido en dos partes, el artículo analiza primero las estrategias estilísticas de cada novela, donde se intercalan discursos históricos, periodísticos y literarios, para fijar la narrativa ficcional en la experiencia personal de su autora. En segunda instancia, demuestra la conexión que se establece entre degradación ambiental, masculinidad hegemónica y violencia de género, y concluye con una discusión del papel del lenguaje y de la literatura en las ecologías naturales, humanas y culturales de las novelas estudiadas.

\section{Ficciones de crisis desde el testimonio personal}

La novia oscura inicialmente establece su referente histórico a través de la descripción del pueblo de Tora, topónimo indígena de la actual Barrancabermeja (Lindsay, 2003, p. 50), la ciudad que fue el centro de operaciones de la Tropical Oil Company en los campos petrolíferos de Mares desde 1919 hasta 1951, cuando la concesión se revirtió al gobierno colombiano (Carvalho, 2007, p. 45). Descrita como "la ciudad de las tres pes, Putas, Plata y Petróleo" (Restrepo, 1999, p. 12), Tora aloja a una gran 
población masculina itinerante empleada por la compañía petrolera que en la novela conserva su nombre histórico: la Tropical Oil Company. Como en una especie de Bildungsroman, la novela cuenta la llegada y eventual partida de su joven protagonista, Sayonara, y se centra en el universo ginocéntrico de la Catunga, la zona roja de Tora. Tras el telón de fondo de las operaciones de la Tropical Oil Company, La novia oscura cuenta las complicidades de los cuatro pilares de autoridad - el Estado, la Iglesia, el Ejército y la empresa multinacional- en el gobierno de la comunidad local, con el fin de maximizar la productividad y minimizar la perturbación de la extracción de petróleo. Aunque los indicios temporales son imprecisos, el paro de los trabajadores de "la Troco" junto a la represión violenta del Estado sitúan el cuadro cronológico de la novela en el último de la serie de protestas que tuvo lugar en Barrancabermeja entre los años 30 y 40, a principios de la época de la Violencia.

Lloyd Davies (2007) ha señalado la variedad de referencias en La novia oscura a explotaciones históricas, que se extienden "from the pursuit and capture of Indians [sic] [...] to the unprincipled conduct of the Tropical Oil Company, which treats its workers with disdain and pollutes the environment in which it operates" (p. 1038). La conexión entre el desprecio por la comunidad local y por el ambiente natural se percibe desde las primeras páginas de la novela, cuando el personaje secundario, Sacramento, evoca la contaminación histórica de las aguas del Magdalena: "Ya se jodió el mundo [...] Hasta el agua sabe a gasolina" (Restrepo, 1999, p. 17). Para Ana María Mutis, la novela de Restrepo es precursora de textos más recientes - tales como El desbarrancadero (2001), de Fernando Vallejo, y Angosta (2003), de Héctor Abad Faciolince- que trazan un vínculo directo entre la contaminación de las fuentes de agua en Colombia con derrames de petróleo, efluentes industriales y desechos urbanos, y la marginalización, la desigualdad, la pobreza y la violencia: "La literatura colombiana reconoce que, además de cadáveres, el río carga desechos y contaminación; la narrativa contemporánea es repleta de corrientes nauseabundas que sirven de vertederos de desechos tóxicos y desperdicios humanos" (Mutis, 2013, p. 146). De este modo, Mutis corrobora la observación de Barbas-Rhoden (2014) en cuanto a que la consciencia ecológica de textos latinoamericanos se trata frecuentemente de manera implícita junto a la experiencia de modernidad en la región y del efecto de las fuerzas impulsoras de la globalización y de políticas 
económicas neoliberales (p. 83), como quedó ilustrado en Las venas abiertas de América Latina de Eduardo Galeano (1971).

A la par del escenario, la trama y la temporalidad, la estructura narrativa también fortalece la asociación entre la explotación del ambiente natural y la de los individuos que viven y trabajan en la zona. La narradora es una periodista de Bogotá encargada de investigar el robo de petróleo en Tora por una banda local, una investigación que se interrumpe cuando encuentra una fotografía de una mujer, tomada unos cincuenta años atrás, cuyo aspecto le intriga y la impulsa a hacer averiguaciones sobre su identidad e historia. Restrepo implícitamente invita a sus lectores a asociar a la autora con la narradora cuando, en una entrevista con Lina María Álvarez (2016), explica su propia investigación del descontento laboral de los empleados de Ecopetrol en Barrancabermeja. En una estrategia metodológica y estilística típica de la obra de Restrepo, la narradora de La novia oscura se interpone con frecuencia en su propia narración para comentar el proyecto investigativo detrás de la historia relatada. ${ }^{1}$ Estas interjecciones, junto a la transcripción de sus entrevistas con las ancianas y otros residentes del barrio La Catunga, operan tanto a nivel ficcional como metaficcional: "su delicada observación me tomó por sorpresa, me llegó como una peculiar clave para descifrar aquel mundo, con la cual este libro no debía desentonar, y me obligó a repensar cosas que he escrito atrás" (Restrepo, 1999, p. 173). De esta manera, la narración alterna entre la historia de Sayonara y la Tropical Oil Company, y la explicación de la investigación y escritura de esta misma historia en un presente contemporáneo al momento de publicación de la novela a fines de los años 90, una contemporaneidad confirmada por una referencia a los "sicarios en las comunas de Medellín" (p. 58).

A diferencia de La novia oscura, el proyecto investigativo detrás de Le Club des miracles relatifs no se justifica en la misma novela, sino en una entrevista con Lucas Mascarello (2015). Ahí la escritora canadiense, que vive entre París y Suiza y que escribe principalmente en su segunda lengua, la francesa, describe en términos apocalípticos una visita que hizo en abril de 2014 a las operaciones de fracturación hidráulica (fracking) en las arenas bituminosas de Fort McMurray. El impacto de la visita sobre la autora se revela en la urgencia con la que publicó los dos textos que fueron el fruto de esta experiencia: el ensayo "Alberta: l'horreur merveilleuse" ["Alberta: el horror maravilloso"], en 2015, y la novela que

1 Otros ejemplos paradigmáticos de esta metodología por esta autora son La isla de la pasión (1989) y Dulce compañía (1995). 
es el objeto de este análisis, en 2016. Publicado en la obra colectiva Brut: la ruée vers l'or noir [Crudo: la fiebre del oro negro] (2015), el ensayo aporta el referente histórico de las preocupaciones que son representadas en la novela. En contraste con Restrepo, Huston hace una distinción nítida entre las formas ficcionales y no-ficcionales en estos dos textos distintos que, por su contenido y momento de publicación, pueden leerse como textos paralelos.

Adoptando, como La novia oscura, la forma de Bildungsroman, Le Club des miracles relatifs relata la infancia, adolescencia y juventud de su protagonista, Varian, quien nació en 1979 en la "Île Grise" ["Isla Gris"], cuya población es económica y socialmente devastada cuando la sobrepesca obliga a las autoridades a imponer una moratoria sobre la industria pesquera. Los capítulos que narran la infancia de Varian se intercalan con los que relatan los siete años pasados en la distopía transnacional y babélica de Luniville a partir de 2001, donde "les habitants parlaient cinquante langues différentes mais n'avait rien à se dire" ["los habitantes hablaban cincuenta lenguas diferentes, pero no tenían nada que decirse"] (Huston, 2016, p. 300). ${ }^{2}$ La descripción del boom petrolero en Luniville, en 2001, cuando "les compagnies d'ambrosie commençaient tout juste à prendre la mesure du fabuleux potentiel des sables" ["las compañías de ambrosía justo comenzaban a darse cuenta de la dimensión del fabuloso potencial de las arenas"] (Huston, 2016, p. 130), ${ }^{3}$ refleja la expansión de la explotación de las arenas bituminosas canadienses en el siglo xxI que atrajo a empresas multinacionales, y tras ellas un ejército de trabajadores del mundo entero, en lo que Huston y sus coautores describen en Brut como "la fiebre del oro negro". Como lo explican Susan Ireland y Patrice Proulx en uno de los pocos artículos hasta ahora publicados sobre la novela, se puede reconocer en los nombres ficticios de los lugares que figuran en la novela sus referentes históricos: Alberta se disfraza como Terrebrute; Fort McMurray adopta el nombre de Luniville; Newfoundland se convierte en la Île Grise; Canadá aparece como OverNorth, y Estados Unidos figura como UnderSouth (Ireland \& Proulx, 2018). La narrativa rebosa de neologismos que evocan el "advenimiento de una humanidad inhumana" (Mascarello, 2015) en un pueblo dirigido hacia la adquisición material, como lo indica su nombre - Luniville-, un derivado de su moneda, "el

Todas las traducciones son de la autora de este artículo.

La presentación tipográfica innovadora utilizada por Huston en esta novela se comenta en la conclusión de este artículo. 
luni”. ${ }^{4}$ Con un telón de fondo de eventos climáticos extremos, temperaturas récord, deforestación y extinción de especies, la novela describe un mundo ecológica y socialmente devastado que lo sitúa plenamente en el género de "environmental apocalypticism" ["apocalipticismo ambiental"] (Buell, 1995, p. 280).

Mientras Restrepo adopta un estilo narrativo que fusiona discursos periodísticos y literarios en una novela que relaciona cuestiones ecológicas con su contexto político, económico y social, Huston mantiene una separación nítida entre los géneros de ficción y no-ficción, como lo demuestra la publicación de dos textos distintos. Como transmisoras de testimonios - ajenos y propios - de momentos de crisis, cada autora convierte su contacto personal - directo o indirecto- con estos escenarios en ficciones literarias que buscan descifrarlos y transmitir un mensaje urgente y motivante a sus lectores. A pesar de las grandes distancias geográficas, temporales y culturales que diferencian a estas dos autoras, $\mathrm{y}$ de los contextos históricos de sus novelas - la Colombia de los años $40 \mathrm{y}$ el Canadá del siglo XXI-, ambas novelas señalan una relación recíproca entre la explotación de recursos naturales y la de sectores marginados de poblaciones locales y globales, como se estudiará a continuación.

\section{Degradación ambiental, masculinidad hegemónica y violencia de género}

La relación simbiótica, en La novia oscura y Le Club des miracles relatifs, entre degradación ambiental, masculinidad hegemónica y violencia de género reitera la afirmación de ecofeministas que declaran que no es posible comprender las consecuencias ecológicamente destructivas de las tendencias dominantes en el desarrollo humano sin comprender el papel de género (Mellor, 1997, p. VII). El ecofeminismo, entendido como un acercamiento teórico que vincula ecologismo y feminismo, encuentra sus orígenes en gran parte (pero no exclusivamente) en los países industrializados del norte (p. 4), pero se debe situar también en el contexto de la participación de mujeres en luchas ecológicas y económicas alrededor del mundo (Mies \& Shiva, 1993). En su análisis de la relación entre el femenismo y el dominio de la naturaleza, Val Plumwood (1993)

$\overline{4} \quad$ El neologismo del nombre del pueblo hace eco del título del documental Brut: Fort McMoney (2013), de David Dufresne, unos de los coautores de Huston en la publicación colectiva Brut: la ruée vers l'ors noir. También es homófono de "loonie", con que se refiere informalmente en el Canadá anglófono al dólar canadiense. Agradezco a Antonio Viselli esta aclaración hecha durante el congreso de la Australian Society for French Studies (2018). 
propone que se incluya la naturaleza como otra categoría de análisis junto a la raza, la clase social y el género en la teorización de formas globales de opresión y de explotación. Las dos novelas aquí analizadas invitan una lectura ecofeminista que sigue las pautas de Plumwood en que se relacionan cuestiones ecológicas con otras de género y de etnicidad, y exigen un examen minucioso del protagonismo del racismo, el neocolonialismo y el capitalismo multinacional, tanto en la degradación ambiental como en la opresión de los sectores más marginados de la población global. Restrepo y Huston demuestran una consciencia aguda del papel de género y de la interseccionalidad en los respectivos contextos colombianos y canadienses de sus novelas, como lo demuestra la representación de la segregación sexual de las comunidades representadas y de los personajes femeninos indígenas, que se analizarán en esta sección.

La segregación sexual de las comunidades mineras retratadas, donde la minería es una actividad masculinizada y su parafernalia se describe en términos sexualizados y fetichistas, resalta la interdependencia entre una masculinidad hegemónica y una feminidad instrumentalizada. En Le Club des miracles relatifs, la misma tierra se asemeja a un cuerpo femenino maltratado, descrita como "cette terre massacrée défigurée violée et horriblement éventrée" ["esta tierra masacrada desfigurada violada yhorriblemente destripada"] (Huston, 2016, pp. 131-132). Los miles de hombres que trabajan en las minas y viven en los campos de trabajo cercanos son a su vez reducidos a cuerpos que "mangent, dorment, respirent, souffrent et font de l'autoassistance [se masturbent]" ["comen, duermen, respiran, sufren y hacen autoasistencia (se masturban)"] (Huston, 2016, p. 15). El empleo para las mujeres en Luniville se limita, en el mejor de los casos, al trabajo de cuidado que responde a las necesidades físicas y psicológicas de los trabajadores y habitantes del pueblo, y en el peor, a la prostitución, una industria en aumento debido la presencia de una población femenina en desventaja social y económica, y una población masculina transitoria de trabajadores mineros "loin de chez eux et sexuellement affamés" ["lejos de sus casas y sexualmente famélicos"] (Huston, 2016, p. 126). La descripción de Huston de una mano de obra masculina que padece de una libido innata e involuntaria reitera argumentos presentados en su libro Reflets dans un oil d'homme [Reflejos en el ojo de un hombre] (2012). Sin embargo, la crítica explícita de la mercantilización y apropiación violenta de los cuerpos de mujeres en Le Club des miracles relatifs es menos indulgente en cuanto a esta pretendida base biológica de la masculinidad. 
Los hombres y las mujeres de La novia oscura son similarmente segregados en el "campo 26" de la Tropical Oil Company, el sitio de extracción, y "La Catunga", la zona roja de Tora que "presta servicio" a la población masculina. Tal segregación sexual en ambas novelas sitúa una población femenina en subordinación sexual y económica a la población masculina de trabajadores, ellos mismos subalternos a la empresa petrolera, llevando a relaciones empobrecidas y violentadas entre hombres y mujeres, y una mercantilización de todo intercambio humano, inclusive hasta la muerte. En Le Club des miracles relatifs, la pérdida de la vida humana se presenta como el daño colateral inevitable de la búsqueda a toda costa de la ganancia material, mientras en La novia oscura la muerte se convierte en oportunidad comercial (Restrepo, 1999, p. 124).

La maquinaria minera también es sometida a una especie de sexualización en cada texto: en Le Club des miracles relatifs, esta es representada como una extensión del cuerpo del hombre, ${ }^{5}$ que aumenta artificialmente su fuerza y su capacidad de actuar sobre el mundo: "leur corpsmachine livre une guerre contre la forêt leurs mains sont des pelles larges de sept mètres leurs jambes des pneus hauts comme un immeuble" ["sus cuerpomáquinas libran una guerra contra el bosque sus manos son palas grandes de siete metros sus piernas son neumáticos altos como un edificio"] (Huston, 2016, p. 133). Cuanto más grande la máquina, más veneración inspira: los camiones gigantescos remplazan a las mujeres desnudas como objetos de deseo en los calendarios fetichistas (p. 305). Por su parte, en La novia oscura, "la torre de perforación experimenta una especie de devenir-mujer, es personificada como la altamente sexuada 'flaca Emilia"' (Davies, 2007, p. 1044), y es descrita en términos de una feminidad estereotípicamente idealizada, como "dócil", "callada” y "cariñosa" (Restrepo, 1999, p. 312). Al permitirle al hombre minero aumentar de manera artificial su fuerza y apoderarse de un objeto inanimado feminizado, la fusión del hombre con la máquina tanto en Terrebrute como en Tora hace alusión a la dominación masculina de un mundo natural feminizado. Tal apropiación del mundo natural se ilustra de la manera más pronunciada en la descripción de las dragas que invaden el río Magdalena en La novia oscura. Según la narradora:

Entendido aquí en referencia únicamente a los hombres, y no en el sentido universalizante para referirse a hombres y mujeres. 
El otrora Gran Río de la Magdalena se me aparecía como una larga ausencia: lenta, negra, recargada de dragas [...] y de otros aparatos metálicos y ortopédicos que la convertían en una prolongación de la refinería, que se extendía en la orilla opuesta oxidando el cielo nocturno con la combustión perpetua de sus altas chimeneas (pp. 133-134).

La presentación de la segregación sexual de las economías laborales en estas novelas reitera los argumentos de ecofeministas que ven una relación directa entre la dominación sistemática de mujeres y naturaleza, y las instituciones del capitalismo patriarcal (Sydee \& Beder, 2001). Para las ecofeministas materialistas, la dominación sistemática de mujeres y naturaleza coincide con un sistema socioeconómico que cristaliza la lógica de los dualismos (razón/naturaleza, humano/animal, masculino/ femenino) que determina una participación diferenciada de los hombres y las mujeres en la sociedad civil y laboral. En particular, algunas ecofeministas materialistas critican la institución del Estado y su papel en la globalización debido a su función en el capitalismo patriarcal (Sydee \& Beder, 2001, p. 281). En el caso de las mujeres de La Catunga, ellas se rebelan en contra de la complicidad del "Estado proxeneta" con los intereses de la multinacional petrolera en la imposición de una revisión médica semanal (Restrepo, 1999, pp. 82-90). Ostensiblemente, una revisión de salud por el bien de las mujeres, la corrupción del personal del puesto de salud revela que estas revisiones son, en realidad, una maniobra para generar ingresos que resultan más rentable que las mismas concesiones mineras, como lo declara una de las mujeres entrevistadas por la narradora: "Un investigador francés que vino por esos años hizo averiguaciones y echó cifras y nos dejó saber que las prostitutas de Tora le pagábamos más al Estado en controles de salud y en multas, que la Tropical Oil Company en regalías" (p. 90).

Si la institución de la medicina pública en La novia oscura representa un mecanismo de explotación de las mujeres más marginalizadas de la comunidad, el puesto de salud en Le Club des miracles relatifs, en cambio, pone en evidencia los efectos nocivos del proceso de fracturación hidráulica para sus trabajadores. Enfermero en el Centro de Mantenimiento Respiratorio de la empresa petrolera, AbsoBrut, Varian trata a los empleados por las dificultades respiratorias causadas por las sustancias tóxicas que son descargadas en el proceso de extraer petróleo crudo de las arenas bituminosas. Luego de una fuga en uno de los oleoductos - comparada a una eyaculación, reforzando así la sexualización de la parafernalia 
minera-, los síntomas de contaminación incluyen náusea, vértigo, alucinaciones, quemaduras y problemas de la visión. Mientras La novia oscura señala la complicidad del Estado con la institución de la medicina pública en la explotación de las mujeres, Le Club des miracles relatifs acusa a la empresa minera de poner en riesgo la salud y vida de sus empleados, con plena consciencia del costo personal y ambiental de su actividad, como lo demuestran los panfletos de salud ocupacional de la empresa que son citados por sus personajes (Huston, 2016, pp. 306-320).

Entre los escenarios presentados en las dos novelas, es el personaje ambivalente de Varian quien más decisivamente demuestra la relación recíproca entre masculinidad hegemónica y violencia de género en la sociedad minera de Terrebrute. Como un joven tímido, delgado y dotado de una inteligencia precoz, Varian no corresponde al modelo de masculinidad normativa idealizado en su contexto espacio-temporal. Víctima de matoneo en la infancia y embrutecido por su entorno, Varian desarrolla una aversión misantrópica, sobre todo hacia las mujeres, con quienes evita a toda costa entrar en contacto físico o visual. Inventa los neologismos "marmottes" y "culpettes" para designar a las dos categorías en las cuales divide a todas las mujeres, ya sea como "arpías" — "féministes depuis des millénaires les marmottes savent tout faire tomber enceinte voter accoucher diriger des entreprises élever des enfants écrire des thèses" ["feministas desde hace milenios, las marmottes saben hacer de todo quedar embarazadas votar dar a luz dirigir empresas criar niños escribir tesis"] (Huston, 2016, p. 64) - o "putas" que "enfoncent leurs griffes et leurs crocs dans notre chair sucent notre sang et notre moelle avalent notre semence et nos sous" ["clavan sus garras y sus colmillos en nuestra carne chupan nuestra sangre y nuestra médula tragan nuestra simiente y nuestra plata"] (p. 241). Las mujeres virtuales, en imágenes cada vez más violentas, son las únicas con quienes busca entrar en contacto, lo que le lleva a una adicción patológica a la masturbación y, eventualmente, al abuso y asesinato de seis mujeres. La vulnerabilidad de las mujeres que son acosadas, atacadas y estranguladas por Varian ilustra las condiciones precarias en las cuales viven en Luniville, una precariedad desencadenada o agravada por el exilio, la migración económica, la pobreza, la violencia doméstica, la adicción, el conservatismo religioso o el racismo. Las historias individuales de las víctimas de Varian son relatadas en capítulos intercalados con los que cuentan el pasado lejano (la infancia) 
y el pasado reciente (desde la llegada a Luniville) de Varian, y ocurren en un contexto de una violencia física y sexual generalizada. Cuando Varian es detenido por las fuerzas de seguridad de Terrebrute, supone que es por los crímenes cometidos contra sus víctimas. Es solo cuando es interrogado y torturado por su supuesta participación en una red local de militantes ecologistas que descubre que en realidad es acusado de "ecoterrorismo". En esto se ve reflejada en la novela la creciente persecución actual contra activistas ambientales en las Américas, su frecuente caracterización en el contexto norteamericano como "ecoterroristas" (Buell, 2009), y su extrema vulnerabilidad en el contexto latinoamericano (Watts \& Vidal, 2017).

La sincronización del Estado con las empresas petroleras multinacionales en Le Club des miracles relatifs y La novia oscura inscribe una dinámica de poderes que refleja las advertencias de ecocríticos postcoloniales y feministas sobre el impacto nefasto de la globalización y la consolidación del poder de las empresas multinacionales (Mies \& Shiva, 1993; Sydee \& Beder, 2001). Estas relaciones de poder conllevan, en ambas novelas, a intersecciones de desventaja que son más pronunciadas para los personajes femeninos pertenecientes a minorías étnicas y, en particular, indígenas. Los personajes femeninos indígenas en ambas novelas ocupan posiciones particularmente vulnerables y son desproporcionalmente afectados por el impacto de las crisis sociales y ambientales que se desencadenan en sus comunidades. De las seis víctimas de Varian, es la experiencia de Marnie Vermilion la que más se destaca en el (anti)clímax narrativo del penúltimo capítulo de Le Club des miracles relatifs y que pone en evidencia el resultado trágico de estas intersecciones. El capítulo abre con un llamado de atención al índice desproporcional de asesinatos y desapariciones de mujeres indígenas en Canadá a principios del siglo Xxi: "Ces dernières années, un bon millier d'entre elles ont été rayées de la carte: assassinées ou 'disparues" ["En estos últimos años, más de mil de ellas han sido eliminadas: asesinadas o 'desaparecidas"'] (Huston, 2016, p. 393). ${ }^{6}$ De una comunidad indígena en Peltham, una versión ficcionalizada de Fort Chipewyan en el delta del Río Athabasca (Huston, 2015), Marnie es una de las últimas "épaves humaines" ["ruinas humanas"] (Huston, 2016, p. 386) en un pueblo diezmado por el mercurio y el arsénico que fluyen hacia el delta desde el sitio de fracturación hidráulica en Luniville, y que contaminan la tierra, el aire y el agua, envenenan los peces de la zona y acaban con las industrias locales. Con veintinueve

$\overline{6} \quad$ Huston también destaca la vulnerabilidad particular de las mujeres indígenas de Canadá en la novela Danse noire [Danza negra] (2013). 
años, cuatro hijos (una de los cuales falleció a causa de toxicidad ambiental a los once años) y una adicción al crack, Marnie anuncia su "délicieuse peau indigène" ["deliciosa piel indígena"] (Huston, 2016, p. 388) en una página web publicitaria de servicios sexuales donde sus orígenes indígenas la exponen a un riesgo mayor de violencia a manos de los que la contratan.

Una jerarquización étnica comparable también se observa en la zona roja de Tora, donde las mujeres indígenas del barrio La Catunga ocupan "el último escalón" (Restrepo, 1999, p. 15) de una gama social determinada por la etnicidad, evidenciando una continuidad entre estas dos narrativas americanas - si bien no es limitada al contexto americano (Mies \& Shiva, 1993) - en la coincidencia neocolonial de la desigualdad social, la feminidad y la indigeneidad (Heffes, 2014, p. 17). Mientras la narradora de La novia oscura denuncia el racismo y la marginalización a los cuales son sujetas las mujeres indígenas, también emplea varios estereotipos en su evocación, utilizando, por ejemplo, clichés para referirse a "las indígenas con sus racimos de hijos" (Restrepo, 1999, p. 91) y refiriéndose a ellas únicamente de manera colectiva, en contraste con las otras mujeres de la novela que son presentadas como individuos. Aunque la historia personal y familiar de Sayonara es evidencia del racismo estructural de la sociedad y de la desventaja que sufre por ser la hija de una mujer guahiba y de un hombre "blanco", ella frecuentemente es presentada en términos exóticos - como, por ejemplo, en la alusión que hace el mismo título de la novelay descrita como cercana a la naturaleza, sea por su asociación con el río Magdalena (vía por la cual aparece y desaparece en el pueblo y por ende, en la novela) o por su comparación con animales tales como gatos, panteras y serpientes (pp. 87, 145, 146). En efecto, la misma premisa de la investigación de la narradora sobre la historia personal de Sayonara se inicia con el aire "enigmático" y "seductor" que percibe en la fotografía ya mencionada.

Mutis (2013) propone una interpretación de la caracterización de Sayonara, y particularmente de su asociación con la naturaleza, como un refuerzo del mensaje ecológico de la novela en cuanto incentiva a los lectores a desestabilizar una visión antropocéntrica del mundo natural, que ve a los humanos en una relación jerárquica frente al resto del mundo natural y animal. Sin embargo, la posibilidad de que la figura de Sayonara refuerce "la consciencia ecológica de la novela" a través de su fusión con la naturaleza con el fin de resaltar "la alianza entre los humanos y el ambiente natural" (p. 154) permanece limitada mientras ella sea el único personaje 
a ser fusionado con el mundo natural, reiterando así la asociación (neo) colonial de personas $-\mathrm{y}$ sobre todo mujeres- indígenas con el mundo natural. Hasta que toda la humanidad sea pensada como parte del mundo natural, y los personajes indígenas femeninos se presenten en otros términos distinto a "ruinas humanas", la narrativa americana de crisis ambiental y social queda permeada de ambivalencias.

\section{Conclusiones: sobre ecologías humanas y culturales}

Las conclusiones de La novia oscura y Le Club des miracles relatifs reiteran este tono de ambivalencia: Sayonara parte sin explicación de Tora y Varian queda detenido en el centro penitenciario BigMax sin que se indique el resultado de su detención. De esta manera, las novelas de Restrepo y Huston plantean una incertidumbre textual y ponen en duda la insistencia de Dwyer (2010) sobre la tendencia optimista de toda ecoficción (p. 3). Donde algunas ecoficciones pueden adoptar un tono optimista con el fin de movilizar lectores que podrían reaccionar con desespero o desafecto frente a la magnitud de los desafíos presentados por el cambio climático, Restrepo y Huston ofrecen una experiencia de lectura envolvente que combina la seriedad estética y temática de la literatura "culta" con la atracción de la literatura "popular" (Holmes, 2016) para involucrar a sus lectores intelectual y emocionalmente en los escenarios expuestos. Más allá del recurso de una clausura optimista, la interpelación a los lectores se logra en estas dos novelas mediante la presencia de elementos fundamentales de la literatura "popular" - una trama bien definida, personajes que inspiran empatía, un fuerte sentido de arraigo y elementos metaficcionales (Holmes, 2016) - junto con la innovación estilística y temática de la literatura "culta". De esta manera, La novia oscura y Le Club des miracles relatifs indagan en la relación compleja entre literatura, lenguaje y medio ambiente de una manera que recuerda la "ecocrítica biopolítica" de Louise Hardwick (2016). En este acercamiento metodológico, Hardwick critica la distorsión del lenguaje y de la cultura que acompaña la globalización en la valorización de lo prosaico y lo mundano sobre lo poético y los valores abstractos que son la esencia de la humanidad. Según Hardwick, el culto de lo prosaico describe el dogma del consumismo propuesto por las políticas económicas neoliberales al costo de las relaciones humanas y la custodia del mundo natural. El lente crítico que propone Hardwick ilumina las denuncias de Huston y Restrepo sobre la explotación tanto de la humanidad como de la 
naturaleza, donde la comunidad es diezmada social y culturalmente por el proyecto neoliberal, y el lenguaje es manipulado con fines cínicos.

Tanto el contenido como la forma del discurso de Varian demuestran una consciencia de la susceptibilidad del lenguaje a la manipulación, como se ha visto, en la expresión titubeante de sus monólogos interiores, donde sus pausas son tipográficamente representadas con espacios en blanco entre las palabras: "Ici-haut les mots eux-mêmes sont charcutés et châtrés tout est neutralisé par le recours aux abréviations aux euphémismes aux acronymes" ["Aquí arriba las palabras mismas son despedazadas castradas todo es neutralizado por el recurso a las abreviaciones a los eufemismos a los acrónimos"] (Huston, 2016, p. 316). En el "Centro de Mantenimiento Respiratorio", donde Varian trabaja como enfermero, el doctor Luka Romanyuk descontamina los cuerpos de los trabajadores de AbsoBrut mientras su hermana, la única mujer por quien Varian no siente repulsión o desprecio, aparte de su madre, trata sus mentes e imaginaciones. Los hermanos Luka y Leysa fundan un club de lectura al Centro, cuyo nombre retoma las siglas del mismo para llamarse el "Club de los Milagros Relativos", donde Leysa lee a los pacientes los cuentos y poesías de los escritores rusos Anna Akhmátova, León Tolstói y Marina Tsvetáyeva (entre otros), en una tentativa de recuperar los valores humanísticos propios de la literatura y de restaurar las ecologías humanas y culturales que son amenazadas por la manipulación cínica del lenguaje por parte del Estado y las empresas mineras multinacionales, como se ha visto en la mencionada designación de "ecoterroristas" a los activistas ecologistas.

De modo similar, La novia oscura y Le Club des miracles relatifs rescatan el lenguaje del cinismo en obras que buscan conmover a sus lectores e incitarlos a la acción, en un estilo literario comprometido, imbuido de una intención autoral claramente declarada. Al entrar en un pacto directo con las ecologías naturales, humanas y culturales de sus entornos, Restrepo y Huston adoptan una postura ética y moral frente a los dilemas planteados en sus novelas. Si, como lo afirma el crítico Timothy Clark (2011), "the moral impetus behind ecocriticism [...] necessarily commits it to to take some kind of stance, however implicit, on the huge issue of what relationship human beings should have to the natural world' ['el ímpetu moral detrás de la eco-crítica [...] necesariamente lo compromete a tomar alguna postura, aunque sea implícita, frente a la cuestión inmensa de qué relación debería tener los seres humanos al mundo natural” (p. 6), estos 
textos demuestran una clara postura moral con respecto a las relaciones entre seres humanos, y particularmente ante los más vulnerables frente a las apabullantes injusticias de las crisis ambientales y sociales de nuestra época.

\section{Referencias bibliográficas}

Álvarez, L. M. (2016). Las pasiones, delirios y pecados de Laura Restrepo, Revista Bocas 58. Recuperado de: https://www.eltiempo.com/archivo/documento/CMS-16756893 [17.05.2019].

Barbas-Rhoden, L. (2014). Hacia una ecocrítica transnacional: aportes de la filosofía y crítica cultural latinoamericanas a la práctica ecocrítica. Revista de Crítica Literaria Latinoamericana 40 (79), pp. 79-96.

Buell, L. (1995). The Environmental Imagination: Thoreau, Nature Writing, and the Formation of American Culture. Cambridge: Harvard UP.

Buell, L. (2009). What is called ecoterrorism. Gramma: Journal of Theory and Criticism 16, pp. 153-66.

Carvalho, S. E. (2007). In the commercial pipelines: Restrepo's La novia oscura. En Contemporary Spanish American Novels by Women: Mapping the Narrative (pp. 4274). Woodbridge: Tamesis.

Clark, T. (2011). The Cambridge Introduction to Literature and the Environment. Cambridge: Cambridge UP.

David, S. (2016). Eco-Fiction: Bringing Climate Change into the Imagination [Tesis doctoral]. University of Exeter: Exeter.

Davies, L. H. (2007). Imperfect portraits of a postcolonial heroine: Laura Restrepo's $L a$ novia oscura. Modern Language Review 102 (4), pp. 1035-1052.

Dwyer, J. (2010). Where the Wild Books Are: A Field Guide to Ecocriticism. Reno and Las Vegas: University of Nevada Press.

Gordon, T. y Webber J. R. (2008). Imperialism and resistance: Canadian mining companies in Latin America. Third World Quarterly 29 (1), pp. 63-87.

Hardwick, L. (2016). Towards biopolitical ecocriticism: the example of The Manifeste pour les "Produits" de Haute Nécessité. French Studies 70 (3), pp. 362-382.

Heffes, G. (2014). Introducción. Para una crítica latinoamericana: entre la postulación de un ecocentrismo crítico y la crítica de un antropocentrismo hegemónico. Revista de Crítica Literaria Latinoamericana 40 (79), pp. 11-34.

Holmes, D. (2016). Negotiating the middlebrow: women writers and literary stardom in contemporary France. Celebrity Studies 7 (4), pp. 493-508.

Huston, N. (2012). Reflets dans un œil d'homme. Arles : Actes Sud; Montréal : Leméac.

Huston, N. (2015). Alberta : L'horreur merveilleuse. En D. Dufresne, N. Huston, N. Klein, M. Laboucan-Massimo y R. Wiebe. Brut : La ruée vers lor noir (pp. 53-72). Montréal : Lux Éditeur.

Huston, N. (2016). Le Club des miracles relatifs. Arles : Actes Sud; Montréal : Leméac.

Ireland, S. y Proulx P. J. (2018). Human and Inhuman Transformations in Nancy Huston's Dystopian Novel Le Club des miracles relatifs. Nottingham French Studies 57 (3), pp. 311-24. 
Lindsay, C. (2003). "Clear and present danger": trauma, memory and Laura Restrepo's La novia oscura. Hispanic Research Journal 4 (1), pp. 41-58.

Malm, A. (2017). "This is the hell that I have heard of": some dialectical images in fossil fuel fiction. Forum for Modern Languages Studies 53 (2), pp. 121-141.

Martin, D. (2008). Mothers and nomadic subjects: configurations of identity and desire in Laura Restrepo's La novia oscura. Modern Language Review 103 (1), pp. 113-128.

Mascarello, L. (2015). “En Alberta, "l”avènement d"une humanité... inhumaine” : entretien avec Nancy Huston. Reporterre: le quotidien de l'écologie. Recuperado de: https:// reporterre.net/En-Alberta-l-avenement-d-une-humanite-inhumaine [27.04.2019].

Mellor, M. (1997). Feminism and Ecology. New York: New York University Press.

Mies, M. and Shiva, V. (1993). Ecofeminism. London: Zed Books.

Mutis, A. M. (2013). The death of the river and the river of death: the Magdalena River in El amor en los tiempos del cólera and La novia oscura. Hispanic Issues On Line 12, pp. 145-162.

Mutis, A. M. (2014). Del río a la cloaca: la corriente de la crítica ecológica en la literatura colombiana. Revista de Crítica Literaria Latinoamericana 40 (79), pp. 181-200.

Plumwood, V. (1993) Feminism and the Mastery of Nature. London: Routledge.

Posthumus, S. (2012) 'Penser l'imagination environnementale française sous le signe de la différence', Raison publique 17, pp, 15-31.

Restrepo, L. (1999 [2001]). La novia oscura (Bogotá: Alfaguara).

Sydee, J. y Beder, S. (2001). "Ecofeminism and globalism: a critical appraisal". Democracy and Nature 7 (2), 281-302.

Watts, J. y Vidal, J. (2017). Environmental defenders being killed in record numbers globally, new research reveals. The Guardian. Recuperado de https://www. theguardian.com/environment/2017/jul/13/environmental-defenders-being-killedin-record-numbers-globally-new-research-reveals [13.07.2017]. 